\title{
Article \\ Microwave-Assisted Synthesis of Nitrogen and Sulphur Doped Graphene Decorated with Antimony Oxide: An Effective Catalyst for Oxygen Reduction Reaction
}

\author{
Nadia Garino ${ }^{1,2, *(\mathbb{D})}$, Adriano Sacco ${ }^{2, *(\mathbb{D})}$, Angelica Chiodoni ${ }^{2}\left(\mathbb{D}\right.$, Candido F. Pirri ${ }^{1,2}{ }^{(\mathbb{D}}$ and Micaela Castellino ${ }^{1(\mathbb{D})}$ \\ 1 Department of Applied Science and Technology, Politecnico di Torino, Corso Duca degli Abruzzi 24, \\ 10129 Torino, Italy; fabrizio.pirri@polito.it (C.F.P.); micaela.castellino@polito.it (M.C.) \\ 2 Center for Sustainable Future Technologies @Polito, Istituto Italiano di Tecnologia, Via Livorno 60, \\ 10144 Torino, Italy; angelica.chiodoni@iit.it \\ * Correspondence: nadia.garino@polito.it (N.G.); adriano.sacco@iit.it (A.S.)
}

check for

updates

Citation: Garino, N.; Sacco, A.;

Chiodoni, A.; Pirri, C.F.; Castellino,

M. Microwave-Assisted Synthesis of

Nitrogen and Sulphur Doped

Graphene Decorated with Antimony

Oxide: An Effective Catalyst for

Oxygen Reduction Reaction.

Materials 2022, 15, 10. https://

doi.org/10.3390/ma15010010

Academic Editor: Sergio

Morales-Torres

Received: 15 November 2021

Accepted: 16 December 2021

Published: 21 December 2021

Publisher's Note: MDPI stays neutral with regard to jurisdictional claims in published maps and institutional affiliations.

Copyright: (C) 2021 by the authors. Licensee MDPI, Basel, Switzerland. This article is an open access article distributed under the terms and conditions of the Creative Commons Attribution (CC BY) license (https:// creativecommons.org/licenses/by/ $4.0 /)$.

\begin{abstract}
In this study, we report on the facile synthesis of a novel electrocatalysts for the oxygen reduction reaction (ORR), based on reduced graphene oxide (RGO), functionalized with metallic and non-metallic elements. In particular, thanks to a fast one-pot microwave-assisted procedure, we induced, in the RGO graphene lattice, a combined doping with nitrogen and sulphur, and the simultaneous decoration with antimony oxide nanocrystals. The multi-doped-decorated material shows enhanced catalytic performance towards ORR, with respect to common nitrogen- or sulphur-doped carbon-based materials. The presence of co-doping is confirmed by transmission electron microscopy and X-ray photoelectron spectroscopy analysis. The detailed electrochemical characterization shows the simultaneous effects of dopant atoms on the catalytic behavior. In particular, the importance of nitrogen and sulphur atoms in driving the oxygen absorption, together with the role of antimony in enhancing the electrochemical performance toward the ORR, are discussed.
\end{abstract}

Keywords: doping; reduced graphene oxide; antimony; oxygen reduction reaction; microwave

\section{Introduction}

In the global challenge to reduce the use of fossil fuels and the consequent emissions of greenhouse gases, the development of novel, efficient and sustainable energy conversion devices attracts large interest from the scientific community. In this perspective, metal-air batteries [1] and fuel cells are two of the most promising systems [2] capable of facing the need for alternative solutions. Nevertheless, there are still some critical issues that need to be solved before their large-scale commercialization. In particular, the improvement of such devices is strictly connected with the design of efficient and low-cost electrodic materials, with special attention to the cathodic compartment at which the oxygen reduction reaction (ORR) occurs [3].

Limitations in real applications, such as ORR high overpotentials and very slow kinetics, must be overcome by employing a catalyst that is able to drive the reaction with high efficiency towards the four-electron pathway, allowing direct oxygen reduction in a single step. In particular, it is important to hinder the two-electron pathway (which is in competition with the direct four-electron one), because it reduces the system efficiency and produces hydrogen peroxide, which is corrosive and poisonous for cell components [4].

Nowadays, the most widely used ORR catalysts are based on noble metals (in particular Pt) nanoparticles or clusters, supported on carbon nanostructures. Such active materials present high cost [5], low abundance and deteriorative activity of the catalyst, related to noble metal poisoning [6].

For this reason, in the last two decades, many efforts have been spent in studing alternative materials to Pt. In this sense, noble metal-free amorphous carbon or graphenebased electrocatalysts have been widely considered as the most promising alternatives for 
ORR, thanks to their encouraging performance, the excellent electron transport properties of graphene-like materials, their long-term stability and, not least, their low cost [7]. Especially, carbon lattice doping [8], or its decoration with transition metal oxide nanostructures $[9,10]$, has proved to be a winning strategy, by increasing the electrochemical selectivity toward the ORR four-electron pathways.

In this work, we report on the easy and fast synthesis of a novel ORR catalyst that combines (i) the carbon lattice doping with nitrogen and sulphur atoms and (ii) its surface functionalization with antimony oxide $\left(\mathrm{Sb}_{2} \mathrm{O}_{3}\right)$ nanocrystals. The carbon lattice is therefore activated by the presence of nitrogen and sulphur catalytic centers, which affect the carbon electronic structure. This increases the oxygen adsorption and reduces the activation energies requested for the ORR steps [11].

In fact, the active role of nitrogen doping in its different possible configurations (pyridinic, graphitic and pyrrolic) [12] is widely known and understood, while the presence of sulphur doping acts in the electron transport mechanism and towards the electrolyte ions migration, thanks to its peculiar electronic structure [13]. On the other hand, Sb-based materials have been reported as catalyst substrates used to improve the stability in polymer electrolyte fuel cells (generally as doping element of tin oxide) [14] and recently they have been also considered as potential active materials for new generation batteries $[15,16]$. In the present study, it is shown that the presence of antimony oxide nanocrystals further increases the catalytic selectivity, by reaching values close to those of standard Pt-based catalysts [17].

In addition, we propose an innovative and reliable synthetic route: a one-pot microwaveassisted hydrothermal process. Starting from graphene oxide (GO) and thanks to the microwave irradiation, it is possible, in a single step, to obtain the reduction in the GO and the simultaneous doping and functionalization of graphene lattice. In detail, by using thiourea as chemical precursor, it is possible to obtain the doping with both nitrogen and sulphur atoms and, by employing antimony acetate, the decoration of graphene flakes with antimony oxide nanocrystals [18]. The obtained catalysts were named as N-S-RGO/Sb.

The structural characteristic and the morphology of as prepared catalyst were fully characterized by means of X-ray diffraction (XRD) and transmission electron microscopy (TEM). Through X-ray photoelectron spectroscopy (XPS) it was possible to confirm the doping and the complete surface chemistry definition. After the structural characterization, the electrocatalytic tests were carried out using cyclic voltammetry $(\mathrm{CV})$, a rotating ring electrode (RDE), a rotating ring-disk electrode (RRDE) and chronoamperometry (CA) measurements, in order to define the catalytic efficiency towards the ORR.

\section{Materials and Methods}

\subsection{Catalyst Synthesis}

The N-S-RGO/Sb nanocomposite was prepared by following the synthesis procedure reported below. All the synthesis products were used as purchased without any additional treatments.

In a microwave $100 \mathrm{~mL}$ Teflon reactor, provided with pressure and temperature sensors (FlexyWave, Milestone Inc., Shelton, CT, USA), $50 \mathrm{mg}$ of GO (Graphenea Inc., Donostia, Spain) were dissolved in $30 \mathrm{~mL}$ DI water, with $20 \mathrm{mg}$ of thiourea (Sigma-Aldrich, Milano, Italy). Then, $21.5 \mathrm{mg}$ of antimony (III) acetate (Sigma-Aldrich, Milano, Italy) were put and dissolved in the aforementioned mixture. Subsequently, the precursor mixture was sonicated for about $30 \mathrm{~min}$ and the resulting slurry was microwaved for $15 \mathrm{~min}$ at $180{ }^{\circ} \mathrm{C}$ (800 W maximum power). The vessel was then chilled to room temperature. The final suspension was then gathered in tiny vessels, washed using DI water and freeze-dried in order to remove all the water.

\subsection{Structural, Morphological, Compositional and Electrochemical Characterization}

XRD was performed in Bragg-Brentano symmetric geometry by using a PANalytical X'Pert Pro instrument ( $\mathrm{Cu} \mathrm{K} \alpha$ radiation, $40 \mathrm{kV}$ and $30 \mathrm{~mA}$ ) (Malvern Panalytical 
Ltd., Malvern, UK) equipped with an $X^{\prime}$ Celerator detector, in the range $10^{\circ} \leq 2 \theta \leq 90^{\circ}$. Characteristic crystallographic parameters (interlaminar space (d002); crystal stack height $(\mathrm{Lc})$; in-plane crystallite size (La) and number of graphene layers in the crystal (Nc)) were determined as reported in [19].

Samples for TEM were obtained by dispersing, with the support of an ultrasonic bath, the prepared nanocomposite powder in ethanol. A drop of the dispersion was then collected and put on a commercial holey carbon TEM Cu grid, and allowed to evaporate the solvent. TEM analyses were carried out with a FEI Tecnai F20ST (Thermo Fisher Scientific, Waltham, MA, USA) with a field emission gun (FEG), operating at $200 \mathrm{kV}$, both in TEM and STEM modes.

A PHI 5000 Versaprobe X-ray photoelectron spectrometer (Physical Electronics, Chanhassen, MN, USA), equipped with a monochromatic Al K-alpha X-ray source (1486.6 eV), was utilised to check the composite surface chemical composition. A circular spot of $100 \mu \mathrm{m}$ in diameter was selected to gather the photoelectron signal for both the high resolution (HR) and the survey spectra. All samples were subjected to a combined electron and Ar ion gun neutralizer system, to decrease the electrical charging effect during the analysis. The semi-quantitative atomic concentration and fitting procedures were acquired using CasaXPS 2.3.23 dedicated software (Casa Software Ltd., Wilmslow, UK). All core-level peak energies were referenced to $\mathrm{C} 1$ s peak at $284.5 \mathrm{eV}$ and the background contribution in HR scans was subtracted by means of a Shirley function.

A CHI760D electrochemical workstation (CH Instruments Inc., Austin, TX, USA) and a RRDE-3A rotating ring-disk electrode apparatus (ALS, Tokio, Japan) were employed for the electrochemical characterizations. The catalyst samples were deposited onto a glassy carbon disk/Pt ring working electrode (electrode area $0.1256 \mathrm{~cm}^{2}$ ) following the procedure reported in [20]. Unless otherwise specified, all the measurements were carried out in 3-electrode configuration (disk as working electrode $/ \mathrm{Ag} / \mathrm{AgCl}$ as reference electrode $/ \mathrm{Pt}$ coil as counter electrode) in oxygen-saturated $0.1 \mathrm{M} \mathrm{KOH}$ aqueous electrolytic solution with 2500 RPM rotation speed. All the potentials are always referred to the reversible hydrogen electrode (RHE).

For the $\mathrm{CV}$ tests, the potential was scanned from $0.18 \mathrm{~V}$ to $1.18 \mathrm{~V}$ with a rate of $10 \mathrm{mV} / \mathrm{s}$ in both $\mathrm{O}_{2}$ - and $\mathrm{N}_{2}$-saturated electrolytic solutions. For the $\mathrm{RDE}$, the potential range was $0.18 \mathrm{~V}-1.18 \mathrm{~V}$ with a scan rate of $5 \mathrm{mV} / \mathrm{s}$, while rotation speed was varied in the range 400-2500 RPM. For the RRDE measurements, a 4-electrode configuration (disk/ring/reference/counter electrodes) was adopted. The disk electrode was scanned from $0.18 \mathrm{~V}$ to $1.18 \mathrm{~V}$ (scan rate $5 \mathrm{mV} / \mathrm{s}$ ) and the ring electrode was fixed at $1.18 \mathrm{~V}$. For the $\mathrm{CA}$, the potential was fixed at $0.68 \mathrm{~V}$.

The results obtained on N-S-RGO/Sb were compared to those of a commercial available material, namely a Pt/C catalyst (20 wt\%, Sigma-Aldrich, Milano, Italy).

\section{Results and Discussion}

\subsection{Structural and Morphological Analysis}

The structural characteristic of the N-S-RGO/Sb sample was evaluated with X-ray diffraction. In Figure 1a, the XRD pattern of the N-S-RGO/Sb sample is reported. It shows two peak groups. The first, labelled with asterisk, with a main [001] peak at $23.88^{\circ}$, and a second [100] peak located at $42.93^{\circ}$, is assigned to RGO. By analizing the RGO peaks as reported in [19], a $\mathrm{d}_{002}$ of $0.37 \mathrm{~nm}$, a crystal stack height Lc of 2.31, an in-plane crystallite size La of 4.95 and number of graphene layers in the crystal Nc of 6.19 have been found. With respect to the well-known graphite $d_{002}$ peak at $0.34 \mathrm{~nm}$, the $d_{002}$ value takes into account both the graphene oxide reduction process and the $\mathrm{N}$ and $\mathrm{S}$ doping, which, on the whole, contribute to the widening of the RGO peak, thus evidencing a material with an increased structural desorder with respect to grahene or graphite. The $d_{002}$ of $0.37 \mathrm{~nm}$ is in line with those found for other graphene oxide reduction techniques [19], while for the other parameters, they are in the same range of other RGO materials or slighly higher (number of graphene layers in the crystals) than those reported. 

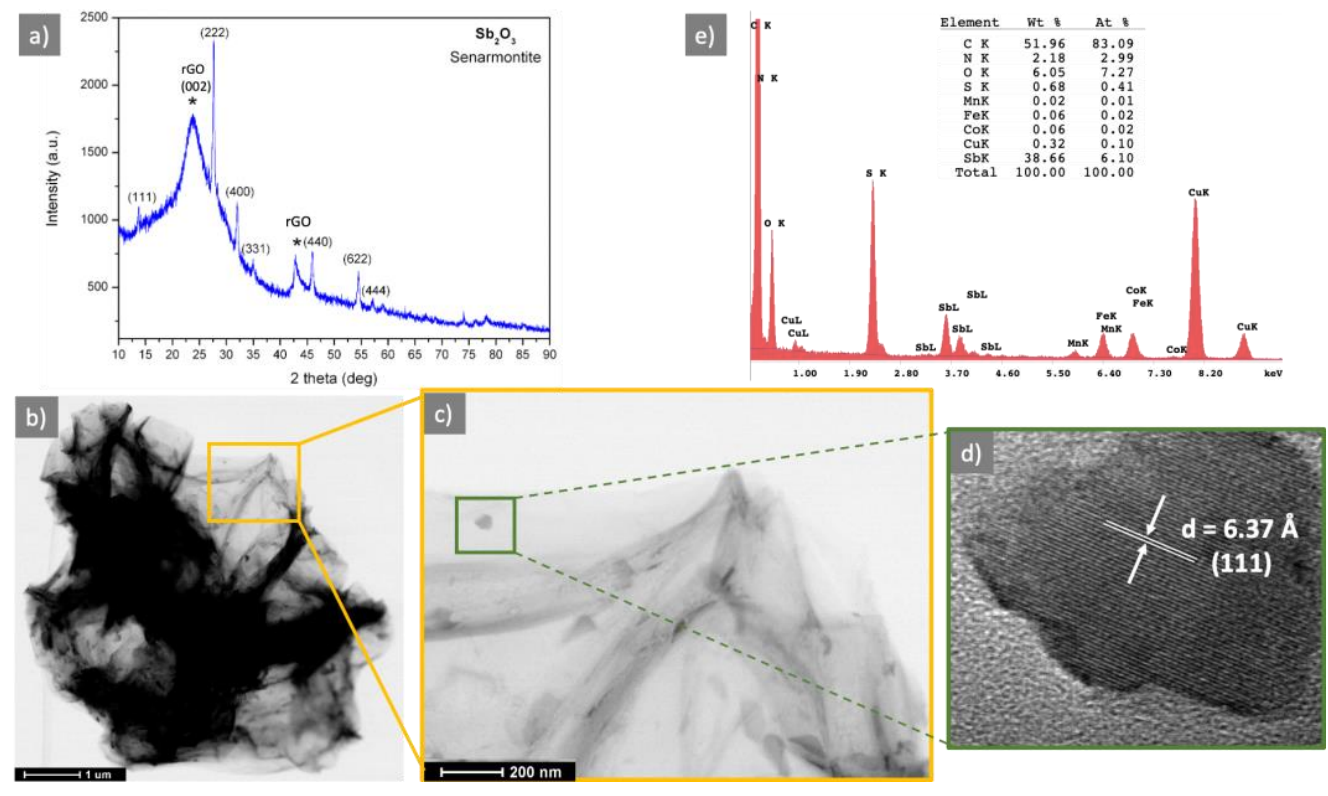

Figure 1. Structural and morphological characterizations of N-S-RGO/Sb sample. (a) XRD (* indicate rGO reflections); (b) STEM characterization of a N-S-RGO/Sb flake; (c) magnification of the orange region in (b); (d) high resolution TEM characterization of a representative crystal decorating the N-S-RGO/Sb flake; (e) EDX spectrum of N-S-RGO/Sb sample.

The second set of peaks has been assigned to $\mathrm{Sb}_{2} \mathrm{O}_{3}$ (senarmontite JCPDL 01-071-0365). The $\mathrm{Sb}_{2} \mathrm{O}_{3}$ peaks are very sharp, giving evidence of a good crystalline quality. No other crystalline phases, e.g., metallic $\mathrm{Sb}$ or other antimony oxides, have been identified.

The morphological feature of the sample has been assessed wih transmission electron microscopy. In Figure $1 \mathrm{~b}$ the STEM image shows a representative micrometric flake of $\mathrm{N}-\mathrm{S}-\mathrm{RGO} / \mathrm{Sb}$, composed of several layers. It can be noticed that, after the GO reduction/doping process, the RGO structure is not damaged and the layers-although in some part wrapped-appear as good quality layers. The STEM magnification in Figure 1c shows elongated cystals, about $100 \mathrm{~nm}$ long, decorating the single layers of N-S-RGO/Sb flake. These crystals, as evident from the high resolution TEM image in Figure 1d, are single crystals, identified as $\mathrm{Sb}_{2} \mathrm{O}_{3}$ senarmontite, thus confirming the XRD findings.

Energy dispersive X-ray (EDX) spectroscopy has been used to confirm the presence of $\mathrm{N}$ and $\mathrm{S}$ in the sample. In Figure 1e the EDX spectrum is reported, together with a semiquantitative elemental analysis. It shows clearly the presence of $\mathrm{C}, \mathrm{N}, \mathrm{S}, \mathrm{Sb}$ and $\mathrm{O}$, together with $\mathrm{Fe}$ and $\mathrm{Co}$, due to the electromagnetic lenses, $\mathrm{Cu}$, due to the copper grid and a contamination of Mn.

\subsection{XPS Analysis}

XPS analysis has been performed in order to obtain detailed information regarding element oxidation states, their chemical enviroment and relative allotropic form. Survey spectrum (not reported) highlights the presence of C (82.6 at.\%), O (11.5 at.\%), N (3.2 at.\%), S (2.6 at.\%) and $\mathrm{Sb}(0.2$ at.\%). No further elements have been detected. The C1s HR spectrum (see Figure 2a) shows a well-reduced graphene oxide signal, since the chemical shifts due to $\mathrm{C}$ and $\mathrm{O}$ bonds have been highly reduced, if compared with a starting commercial GO material [21]. From the deconvolution procedure, we obtained five pseudo-Voigt curves, which have been associated to: $\mathrm{sp}^{2} \mathrm{C}-(\mathrm{C}, \mathrm{H})$ at $284.5 \mathrm{eV}, \mathrm{C}-(\mathrm{O}, \mathrm{N}, \mathrm{S})$ at $285.3 \mathrm{eV}$, $\mathrm{C}=\mathrm{O}$ at $286.8 \mathrm{eV}, \mathrm{O}-\mathrm{C}=\mathrm{O}$ at $288.7 \mathrm{eV}$ and the $\pi-\pi^{*}$ transition at $290.7 \mathrm{eV}$ [20]. The N1s peak (Figure 2b) shows the well-known chemical shifts due to nitrogen atoms doping in a graphene-like matrix, due to pyrrolic- $\mathrm{N}(399.6 \mathrm{eV})$ and graphitic- $\mathrm{N}(400.9 \mathrm{eV})$-already discussed in our previous work [22]. The second dopant element, introduced in the graphene structure thanks to the use of thiourea, which reduces and dopes the C-based 
material simultaneously, is sulphur. Its HR spectrum (Figure 2c) shows the presence of multiple peaks, due to the cohesistence of three different oxidation states, due to: sulphide species $(163.5 \mathrm{eV})$, thiol group $(163.9 \mathrm{eV})$ and sulphate $(168.5 \mathrm{eV})$ [23]. We can easily affirm that no $\mathrm{M}-\mathrm{SbS}_{2}$ (where $\mathrm{M}$ is a metal) or $\mathrm{Sb}_{2} \mathrm{~S}_{3}$ are present in this material, since the chemical shifts expected for this kind of bonds should be located in the range 161.1-161.6 eV [24,25], while our S2p spectrum does not show any component in that region. In order to obtain information from the Sb3d doublet (Figure 2d), we had to deconvolute its signal starting from $\mathrm{Sb}_{3} \mathrm{~d}_{3 / 2}$ peak, since the $\mathrm{Sb}_{3} \mathrm{~d}_{5 / 2}$ overlaps with O1s signal. Hence, the intensity and binding energy of $\mathrm{Sb}_{3} \mathrm{~d}_{5 / 2}$ peak have been set by the $\mathrm{Sb}_{3} \mathrm{~d}_{3 / 2}$ peak position and intensity, according to the spin-orbit splitting $(\Delta=9.39 \mathrm{eV})$ and ratio (0.7), and the remaining area is attributed to $\mathrm{O} 1 \mathrm{~s}$ signal. As shown in Figure $2 \mathrm{~d}$, the Sb3d doublet shows only one oxidation state related to $\mathrm{Sb}^{3+}$ [26], in accordance with electron microscopy results previously reported. O1s contribution has been deconvoluted in four peaks associated with $\mathrm{Sb}_{2} \mathrm{O}_{3}(530.6 \mathrm{eV}), \mathrm{C}=\mathrm{O}(531.5 \mathrm{eV})$, sulphate $/ \mathrm{O}-\mathrm{C}=\mathrm{O}(532.4 \mathrm{eV})$ and $\mathrm{C}-\mathrm{O}-(533.3 \mathrm{eV})$ [23]. Thus, we have been able to detect only the presence of antimony oxide $\left(\mathrm{Sb}^{3+}\right)$, which is in accordance with the hypothesis of $\mathrm{Sb}_{2} \mathrm{O}_{3}$ nanoparticles decoration of the graphene matrix, and no doping by $\mathrm{Sb}$ can be supported. Moreover, both the absence of a component in the region $529.1-529.6 \mathrm{eV}$ and a peak at $396.7 \mathrm{eV}$ (in the N1s region, see Figure 2b), which is commonly attributed to $\mathrm{SbN}$ bond [27], let us confirm also the absence of a direct bond between $\mathrm{Sb}$ and $\mathrm{N}$.


Figure 2. N-S-RGO/Sb XPS HR spectra of C1s (a), N1s (b), S2p (c) and Sb3d+O1s (d) regions, together with their deconvolution procedures.

\subsection{Electrochemical Characterization}

The capability of N-S-RGO/Sb composite of carrying out the ORR was assessed through CV measurements. As shown in Figure 3, a reduction peak is present at about $0.72 \mathrm{~V}$ when the curve is acquired on oxygen-saturated solution, while it disappears in nitrogen- 
saturated electrolyte. This peak can be associated with oxygen reduction, in agreement with previously reported results on different graphene-based electrocatalysts [28-30]. Moreover, it is important to notice that the sample exhibits supercapacitor characteristics, as witnessed by the quasi-rectangular shape of the CV. This is typical of high surface area carbon-based materials [31], and suggests the possible employment of the N-S-RGO/Sb composite as an active material for supercapacitor applications [32].

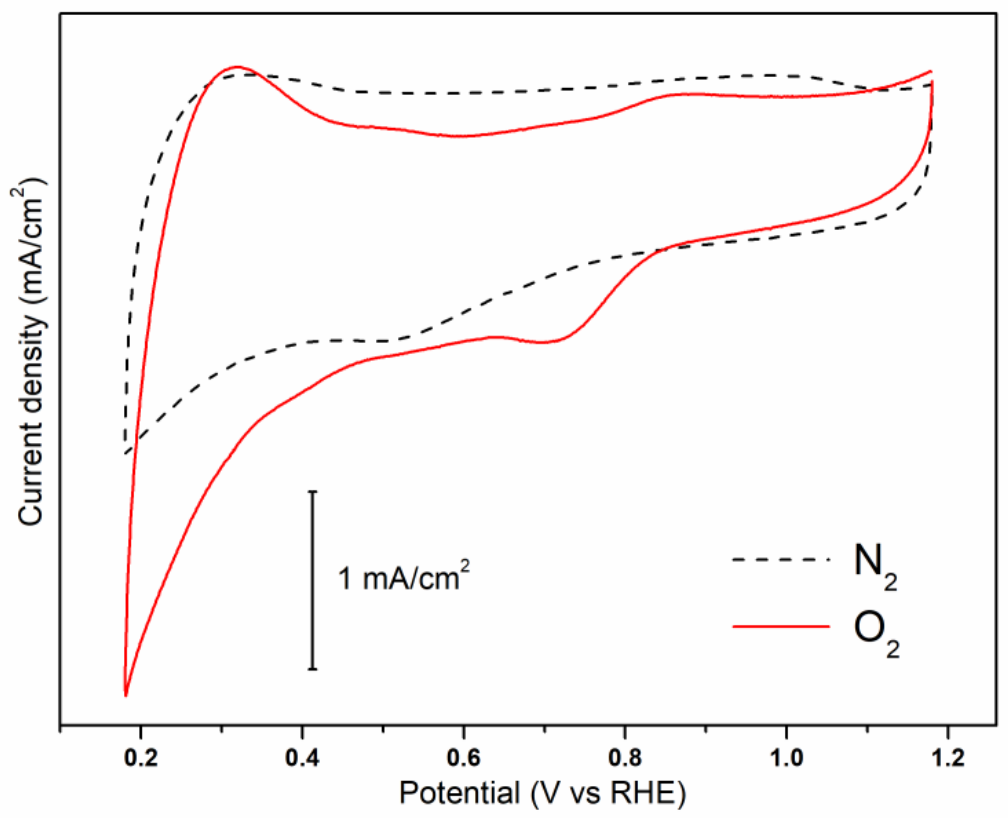

Figure 3. Cyclic voltammograms of the $\mathrm{N}-\mathrm{S}-\mathrm{RGO} / \mathrm{Sb}$ catalyst in $\mathrm{O}_{2}$ - and $\mathrm{N}_{2}$-saturated solutions.

In order to further characterize the ORR activity of N-S-RGO/Sb, RDE measurements were carried out at different rotation rates, as reported in Figure 4. While moving from more positive toward less positive potentials, the curves are characterized by a sudden increase in the cathodic current, $J$, at about $0.79 \mathrm{~V}$. This onset potential $\left(E_{\text {onset }}\right)$ value points to an activation overpotential of $440 \mathrm{mV}$ for the four-electron ORR, which is slightly higher than $290 \mathrm{mV}$ for reference Pt/C catalysts [33]. The curves then exhibit a quasi-plateau region for potential $E$ lower than $0.5 \mathrm{~V}$. In this region, the diffusion-limiting current values become larger while increasing the rotation speed, $\omega$, since the diffusion distance reduces at higher rotation speeds [34]. Finally, for $E \leq 0.35 \mathrm{~V}$, J starts to increase again due to the hydrogen evolution reaction [35]. By considering the curve acquired at $2500 \mathrm{RPM}$, the calculated half-wave potential $E_{1 / 2}$ (i.e., the potential at which the current density is equal to the half of the diffusion-limiting value) is $0.67 \mathrm{~V}$, a value which is similar to [36] or even better [37] than other graphene-based electrocatalysts reported in the literature. By fixing the applied potential, and reporting $1 / J$ as a function of $1 / \sqrt{ } \omega$, it is possible to obtain the Koutecky-Levich $(\mathrm{K}-\mathrm{L})$ plots, which can give information on the selectivity toward the ORR products [38]. In particular, the number, $n$, of electrons involved in the reaction can be obtained by the slope of the $\mathrm{K}-\mathrm{L}$ plots exploiting the following formula:

$$
\frac{1}{J}=\frac{1}{0.62 n F C_{\mathrm{O}_{2}} D_{\mathrm{O}_{2}}^{2 / 3} v^{-1 / 6} \omega^{1 / 2}}+\frac{1}{J_{\mathrm{K}}}
$$

where $J_{\mathrm{K}}$ is the kinetic current density, $F$ is the Faraday constant (equal to $96,485.3 \mathrm{sA} / \mathrm{mol}$ ), $C_{\mathrm{O} 2}$ is the oxygen bulk concentration $\left(1.2 \times 10^{-6} \mathrm{~mol} / \mathrm{cm}^{3}\right), D_{\mathrm{O} 2}$ is the oxygen diffusion coefficient $\left(1.9 \times 10^{-5} \mathrm{~cm}^{2} / \mathrm{s}\right)$ and $v$ is the kinematic viscosity of the electrolyte $\left(9 \times 10^{-3} \mathrm{~cm}^{2} / \mathrm{s}\right)$. The result of the calculation for $E=0.38 \mathrm{~V}$ is reported in the inset of Figure 4. The N-S-RGO/Sb composite is characterized by $n=3.92$, which witnesses a predominant direct reduction to hydroxide ions, rather than indirect reduction to perox- 
ide [39]. It is worth noting that such a high value is among the largest ever reported for graphene-based materials $[40,41]$ and quite close to that of the reference $\mathrm{Pt} / \mathrm{C}(3.95)$ and to the theoretical one (i.e., 4), as shown in the inset of Figure 4. This conclusion assesses the intriguing properties of the proposed catalyst.



Figure 4. ORR polarization curves of the N-S-RGO/Sb catalyst at different rotation speeds (the arrows indicate the onset and half-wave potentials). The inset reports the Koutecky-Levich plots of $\mathrm{N}-\mathrm{S}-\mathrm{RGO} / \mathrm{Sb}$ and of reference $\mathrm{Pt} / \mathrm{C}$ at $0.38 \mathrm{~V}$ potential (the numbers between parentheses represent the calculated electron transfer number values).

The outcomes of the K-L analysis were successfully confirmed by the RRDE measurements, whose results are shown in Figure 5. In particular, the ring current $I_{R}$, which is associated with the production of peroxide species [42], results two orders-of-magnitude lower, with respect to the corresponding disk current $I_{\mathrm{D}}$ for $E \leq 0.7 \mathrm{~V}$. This implies a predominant 4-electron pathway for N-S-RGO/Sb, similarly to commercial Pt/C [43]. The percentage of produced peroxide species $\mathrm{HO}_{2}{ }^{-} \%$ and the number of electrons as a function of the potential can be calculated by employing the measured $I_{\mathrm{R}}$ and $I_{\mathrm{R}}$ through Equations (2) and (3), as follows:

$$
\begin{gathered}
\mathrm{HO}_{2}{ }^{-\%}=200 \times \frac{I_{\mathrm{R}} / N}{I_{\mathrm{D}}+I_{\mathrm{R}} / N} \\
n=4 \times \frac{I_{\mathrm{D}}}{I_{\mathrm{D}}+I_{\mathrm{R}} / N}
\end{gathered}
$$

where $N$ is the current collection efficiency of the Pt ring. Selectivities toward hydroxide larger than $90 \%$ can be obtained with N-S-RGO/Sb for $E \leq 0.7 \mathrm{~V}$, with corresponding $n$ values larger than 3.8 in this potential range (Figure $5 \mathrm{c}$ ). The obtained results are only slightly lower than reference $\mathrm{Pt} / \mathrm{C}$ catalysts, i.e., $\mathrm{HO}_{2}-\% \leq 5 \%, n \geq 3.9$.

It is important at this point to clarify the role of the co-doping and the antimony oxide decoration on the ORR performance. Based on our previous study, in which we fabricated N-doped RGO employing urea as reducing agent instead of thiourea [22], we can affirm that the co-doping is effective in improving the selectivity toward the direct reduction. In fact, the bare nitrogen doping guarantees a mixed 2-4-electron pathway $(n=3.38)$, while this novel co-doped catalyst is characterized by predominant 4-electron 
reduction. Moreover, we already demonstrated $[9,22]$ that the decoration of N-RGO with transition metal oxides ( $\mathrm{Sn}, \mathrm{Fe}$ ) further enhances the ORR selectivity. We thus expect that the same role can be played here by the $\mathrm{Sb}_{2} \mathrm{O}_{3}$ nanocrystals.
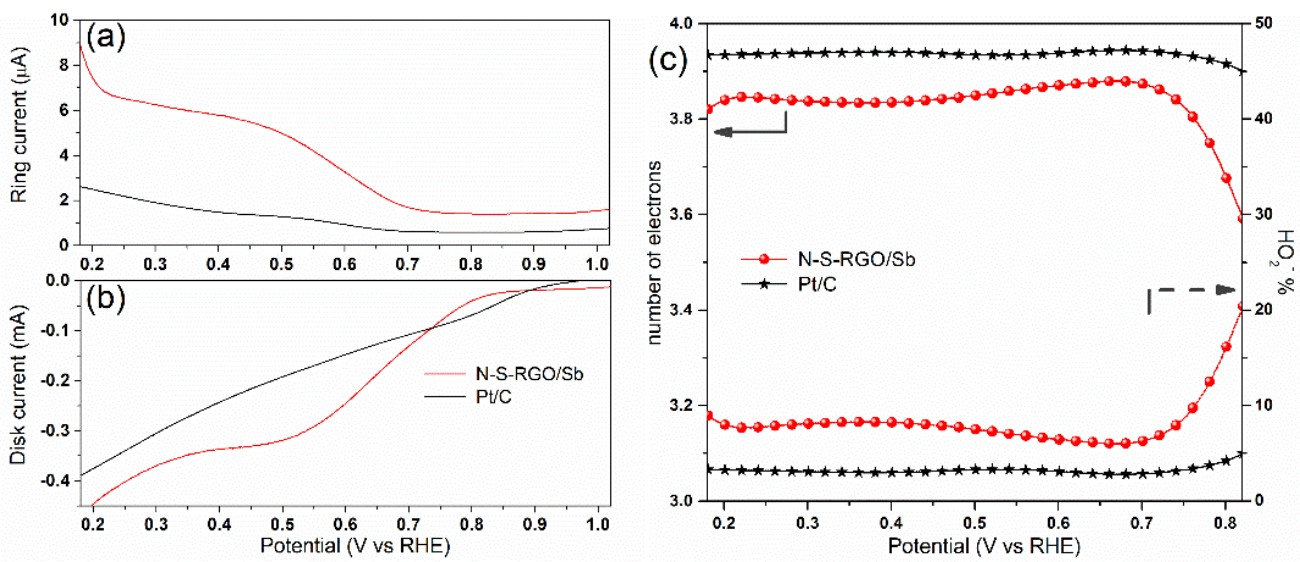

Figure 5. (a) Ring and (b) disk currents of N-S-RGO/Sb and of reference Pt/C measured at $2500 \mathrm{RPM}$ rotation speed; (c) comparison of electron transfer number (left axis) and peroxide percentage (right axis) calculated from the curves in $(\mathbf{a}, \mathbf{b})$.

In addition to the promising properties reported above, the N-S-RGO/Sb catalyst is also characterized by enhanced durability with respect to the commercial $\mathrm{Pt} / \mathrm{C}$. In fact, due to different reasons, such as the detachment of Pt nanoparticles from the $\mathrm{C}$ matrix or upon their aggregation, the ORR activity of the reference catalyst is subjected to a decrease over time [44]. As reported in Figure 6, after $8000 \mathrm{~s}$, the current related to this catalyst is equal to the $73 \%$ of the initial value. On the contrary, the novel N-S-RGO/Sb composite exhibits a decrease of just $4 \%$ in the same period of time. This result can be attributed to the low production of peroxide species in non-precious metal-based catalysts during the reaction [45]. Moreover, we hypothesize that the presence of antimony is beneficial to futher improve the long term stability of the novel catalyst, in agreement to what was reported in [14].

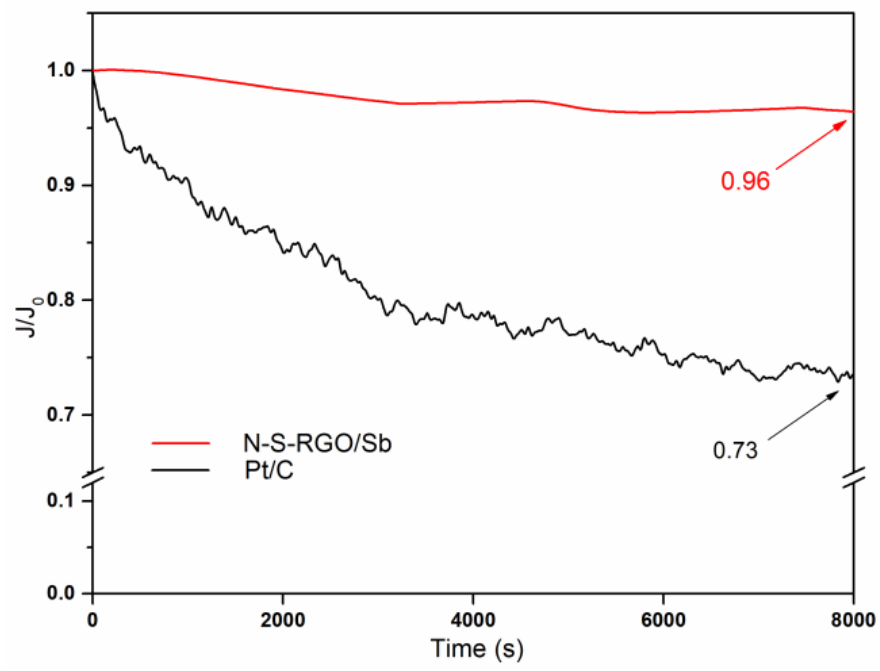

Figure 6. CA of N-S-RGO/Sb and of reference $\mathrm{Pt} / \mathrm{C}$ measured at $0.68 \mathrm{~V}$ potential and $2500 \mathrm{RPM}$ rotation speed normalized with respect to the initial current value (the arrows indicate the values of the normalized currents after $8000 \mathrm{~s}$ ). 


\section{Conclusions}

In this work, we propose the facile microwave-assisted synthesis of a promising ORR catalyst based on a RGO nanocomposite, presenting the graphitic surface functionalization with $\mathrm{Sb}_{2} \mathrm{O}_{3}$ nanocrystals and the co-doping with both nitrogen and sulphur atoms. The synthesis process was evaluated as possible strategy for the preparation of novel graphene-based materials capable of producing, in a single step, doped and/or decorated nanocomposites without damaging the graphitic lattice and removing the need of additional thermal treatments. The results confirm that microwave-assisted processes can be considered as possible substitutes for traditional synthesis procedures, being cost-effective, by drastically reducing time and energy consumption and at the same time enhancing the homogeneity of the final material.

The structural and morphological characterizations of the as-prepared catalyst confirmed both the doping and decoration with nanoparticles. In particular, this N-S-RGO/Sb nanocomposite exhibits very good performance toward ORR, thanks to the electrochemical cooperation between the co-doping and the $\mathrm{Sb}_{2} \mathrm{O}_{3}$ nanocrystals. In fact, this specific configuration showed a synergic effect towards ORR, since the presence of nitrogen and sulphur atoms, as carbon lattice dopants, improved the oxygen absorption and the charge transfer properties; moreover, the presence of antimony oxide nanoparticles further enhanced the efficiency and stability of the catalytic process towards the four electrons pathway.

These findings indicate that this peculiar catalyst can be a potential low-cost and highly durable electrocatalyst for fuel cells and metal-air batteries application, by showing an excellent behavior for the ORR, with electrochemical performance consistent with that of commercial reference $\mathrm{Pt} / \mathrm{C}$ catalyst.

Author Contributions: Conceptualization, N.G.; methodology, N.G.; investigation, A.S., A.C. and M.C.; resources, C.F.P.; data curation, A.S., A.C. and M.C.; writing-original draft preparation, N.G., A.S., A.C. and M.C.; writing-review and editing, N.G., A.S., A.C. and M.C.; visualization, N.G., A.S., A.C. and M.C.; supervision, N.G. and M.C.; funding acquisition, C.F.P. All authors have read and agreed to the published version of the manuscript.

Funding: This research received no external funding.

Institutional Review Board Statement: Not applicable.

Informed Consent Statement: Not applicable.

Data Availability Statement: The data presented in this study is available on request from the corresponding authors.

Conflicts of Interest: The authors declare no conflict of interest.

\section{References}

1. Li, Y.; Gong, M.; Liang, Y.; Feng, J.; Kim, J.-E.; Wang, H.; Hong, G.; Zhang, B.; Dai, H. Advanced zinc-air batteries based on high-performance hybrid electrocatalysts. Nat. Commun. 2013, 4, 1805. [CrossRef]

2. Kinoshita, K. Electrochemical Oxygen Technology; John Wiley \& Sons: New York, NY, USA, 1992; p. 448.

3. Chen, M.; He, Y.; Spendelow, J.S.; Wu, G. Atomically Dispersed Metal Catalysts for Oxygen Reduction. ACS Energy Lett. 2019, 4, 1619-1633. [CrossRef]

4. Li, S.; Hu, Y.; Xu, Q.; Sun, J.; Hou, B.; Zhang, Y. Iron- and nitrogen-functionalized graphene as a non-precious metal catalyst for enhanced oxygen reduction in an air-cathode microbial fuel cell. J. Power Sources 2012, 213, 265-269. [CrossRef]

5. Chen, Z.; Higgins, D.; Yu, A.; Zhang, L.; Zhang, J. A review on non-precious metal electrocatalysts for PEM fuel cells. Energy Environ. Sci. 2011, 4, 3167-3192. [CrossRef]

6. Thompson, S.T.; Wilson, A.R.; Zelenay, P.; Myers, D.J.; More, K.L.; Neyerlin, K.C.; Papageorgopoulos, D. ElectroCat: DOE's approach to PGM-free catalyst and electrode R\&D. Solid State Ion. 2018, 319, 68-76.

7. Shang, Z.; Chen, Z.; Zhang, Z.; Yu, J.; Tan, S.; Ciucci, F.; Shao, Z.; Lei, H.; Chen, D. CoFe nanoalloy particles encapsulated in nitrogen-doped carbon layers as bifunctional oxygen catalyst derived from a Prussian blue analogue. J. Alloys Compd. 2018, 740, 743-753. [CrossRef]

8. Garino, N.; Castellino, M.; Sacco, A.; Risplendi, F.; Muñoz-Tabares, J.A.; Armandi, M.; Chiodoni, A.; Salomon, D.; Quaglio, M.; Pirri, C.F.; et al. Proving the existence of Mn porphyrin-like complexes hosted in reduced graphene oxide with outstanding performance as oxygen reduction reaction catalysts. 2D Mater. 2019, 6, 045001. [CrossRef] 
9. Garino, N.; Sacco, A.; Castellino, M.; Muñoz-Tabares, J.A.; Armandi, M.; Chiodoni, A.; Pirri, C.F. One-Pot Microwave-Assisted Synthesis of Reduced Graphene Oxide/Iron Oxide Nanocomposite Catalyst for the Oxygen Reduction Reaction. ChemistrySelect 2016, 1, 3640-3646. [CrossRef]

10. Ai, L.; Tian, T.; Jiang, J. Ultrathin Graphene Layers Encapsulating Nickel Nanoparticles Derived Metal-Organic Frameworks for Highly Efficient Electrocatalytic Hydrogen and Oxygen Evolution Reactions. ACS Sustain. Chem. Eng. 2017, 5, 4771-4777. [CrossRef]

11. Yang, Z.; Yao, Z.; Li, G.; Fang, G.; Nie, H.; Liu, Z.; Zhou, X.; Chen, X.A.; Huang, S. Sulfur-Doped Graphene as an Efficient Metal-free Cathode Catalyst for Oxygen Reduction. ACS Nano 2012, 6, 205-211. [CrossRef] [PubMed]

12. Lai, L.; Potts, J.R.; Zhan, D.; Wang, L.; Poh, C.K.; Tang, C.; Gong, H.; Shen, Z.; Lin, J.; Ruoff, R.S. Exploration of the active center structure of nitrogen-doped graphene-based catalysts for oxygen reduction reaction. Energy Environ. Sci. 2012, 5, 7936-7942. [CrossRef]

13. Zhai, C.; Sun, M.; Zhu, M.; Song, S.; Jiang, S. A new method to synthesize sulfur-doped graphene as effective metal-free electrocatalyst for oxygen reduction reaction. Appl. Surf. Sci. 2017, 407, 503-508. [CrossRef]

14. Kakinuma, K.; Chino, Y.; Senoo, Y.; Uchida, M.; Kamino, T.; Uchida, H.; Deki, S.; Watanabe, M. Characterization of Pt catalysts on $\mathrm{Nb}$-doped and $\mathrm{Sb}$-doped $\mathrm{SnO} 2-\delta$ support materials with aggregated structure by rotating disk electrode and fuel cell measurements. Electrochim. Acta 2013, 110, 316-324. [CrossRef]

15. Wang, X.; Yang, Z.; Mei, F.; Zhou, Y.; Xu, J.; Jiang, Y. One pot synthesis of Sb2O3/reduced graphene oxide composite anode material for sodium ion batteries. Mater. Lett. 2020, 280, 128565. [CrossRef]

16. Jaramillo-Quintero, O.A.; Benítez-Cruz, M.; García-Ocampo, J.L.; Cano, A.; Rincón, M.E. Enhanced performance of S-doped $\mathrm{Sb} / \mathrm{Sb} 2 \mathrm{O} 3 / \mathrm{CNT} / \mathrm{GNR}$ nanocomposite as anode material in lithium-ion batteries. J. Alloys Compd. 2019, 807, 151647. [CrossRef]

17. Jeon, I.-Y.; Choi, M.; Choi, H.-J.; Jung, S.-M.; Kim, M.-J.; Seo, J.-M.; Bae, S.-Y.; Yoo, S.; Kim, G.; Jeong, H.Y.; et al. Antimony-doped graphene nanoplatelets. Nat. Commun. 2015, 6, 7123. [CrossRef]

18. Wu, Q.; Jeong, T.; Park, S.; Sun, J.; Kang, H.; Yoon, T.; Song, Y.J. Two-dimensional semiconducting and single-crystalline antimony trioxide directly-grown on monolayer graphene. Chem. Commun. 2019, 55, 2473-2476. [CrossRef]

19. Lavin-Lopez, M.P.; Paton-Carrero, A.; Sanchez-Silva, L.; Valverde, J.L.; Romero, A. Influence of the reduction strategy in the synthesis of reduced graphene oxide. Adv. Powder Technol. 2017, 28, 3195-3203. [CrossRef]

20. Garino, N.; Zeng, J.; Castellino, M.; Sacco, A.; Risplendi, F.; Fiorentin, M.R.; Bejtka, K.; Chiodoni, A.; Salomon, D.; Segura-Ruiz, J.; et al. Facilely synthesized nitrogen-doped reduced graphene oxide functionalized with copper ions as electrocatalyst for oxygen reduction. NPJ 2D Mater. Appl. 2021, 5, 2. [CrossRef]

21. Gigot, A.; Fontana, M.; Serrapede, M.; Castellino, M.; Bianco, S.; Armandi, M.; Bonelli, B.; Pirri, C.F.; Tresso, E.; Rivolo, P. Mixed 1T-2H Phase MoS2/Reduced Graphene Oxide as Active Electrode for Enhanced Supercapacitive Performance. ACS Appl. Mater. Interfaces 2016, 8, 32842-32852. [CrossRef]

22. Garino, N.; Sacco, A.; Castellino, M.; Muñoz-Tabares, J.A.; Chiodoni, A.; Agostino, V.; Margaria, V.; Gerosa, M.; Massaglia, G.; Quaglio, M. Microwave-Assisted Synthesis of Reduced Graphene Oxide/SnO2 Nanocomposite for Oxygen Reduction Reaction in Microbial Fuel Cells. ACS Appl. Mater. Interfaces 2016, 8, 4633-4643. [CrossRef] [PubMed]

23. Beamson, G.; Briggs, D. High Resolution XPS of Organic Polymers: The Scienta ESCA 300 Database; John Wiley \& Sons: Chichester, UK, 1992; p. 280.

24. Whittles, T.J.; Veal, T.D.; Savory, C.N.; Welch, A.W.; de Souza Lucas, F.W.; Gibbon, J.T.; Birkett, M.; Potter, R.J.; Scanlon, D.O.; Zakutayev, A.; et al. Core Levels, Band Alignments, and Valence-Band States in CuSbS2 for Solar Cell Applications. ACS Appl. Mater. Interfaces 2017, 9, 41916-41926. [CrossRef]

25. Grigas, J.; Talik, E.; Lazauskas, V. X-ray Photoelectron Spectroscopy of Sb2S3 Crystals. Phase Transit. 2002, 75, 323-337. [CrossRef]

26. Wagner, C.D.; Naumkin, A.V.; Kraut-Vass, A.; Allison, J.W.; Powell, C.J., Jr. NIST X-ray Photoelectron Spectroscopy Database; Measurement Services Division of the National Institute of Standards and Technology (NIST) Technology Services: Gaithersburg, MD, USA, 2012

27. Nolot, E.; Sabbione, C.; Pessoa, W.; Prazakova, L.; Navarro, G. Germanium, antimony, tellurium, their binary and ternary alloys and the impact of nitrogen: An X-ray photoelectron study. Appl. Surf. Sci. 2021, 536, 147703. [CrossRef]

28. Fei, H.; Ye, R.; Ye, G.; Gong, Y.; Peng, Z.; Fan, X.; Samuel, E.L.G.; Ajayan, P.M.; Tour, J.M. Boron- and Nitrogen-Doped Graphene Quantum Dots/Graphene Hybrid Nanoplatelets as Efficient Electrocatalysts for Oxygen Reduction. ACS Nano 2014, 8, 10837-10843. [CrossRef]

29. Wu, J.; Ma, L.; Yadav, R.M.; Yang, Y.; Zhang, X.; Vajtai, R.; Lou, J.; Ajayan, P.M. Nitrogen-Doped Graphene with Pyridinic Dominance as a Highly Active and Stable Electrocatalyst for Oxygen Reduction. ACS Appl. Mater. Interfaces 2015, 7, 14763-14769. [CrossRef] [PubMed]

30. Bhange, S.N.; Unni, S.M.; Kurungot, S. Graphene with Fe and S Coordinated Active Centers: An Active Competitor for the Fe-N-C Active Center for Oxygen Reduction Reaction in Acidic and Basic pH Conditions. ACS Appl. Energy Mater. 2018, 1, 368-376. [CrossRef]

31. Fellinger, T.-P.; Hasché, F.; Strasser, P.; Antonietti, M. Mesoporous Nitrogen-Doped Carbon for the Electrocatalytic Synthesis of Hydrogen Peroxide. J. Am. Chem. Soc. 2012, 134, 4072-4075. [CrossRef] 
32. Pedico, A.; Lamberti, A.; Gigot, A.; Fontana, M.; Bella, F.; Rivolo, P.; Cocuzza, M.; Pirri, C.F. High-Performing and Stable Wearable Supercapacitor Exploiting rGO Aerogel Decorated with Copper and Molybdenum Sulfides on Carbon Fibers. ACS Appl. Energy Mater. 2018, 1, 4440-4447. [CrossRef]

33. Lemes, G.; Sebastián, D.; Pastor, E.; Lázaro, M.J. N-doped graphene catalysts with high nitrogen concentration for the oxygen reduction reaction. J. Power Sources 2019, 438, 227036. [CrossRef]

34. Tan, Y.; Xu, C.; Chen, G.; Fang, X.; Zheng, N.; Xie, Q. Facile Synthesis of Manganese-Oxide-Containing Mesoporous NitrogenDoped Carbon for Efficient Oxygen Reduction. Adv. Funct. Mater. 2012, 22, 4584-4591. [CrossRef]

35. Sacco, A.; Garino, N.; Lamberti, A.; Pirri, C.F.; Quaglio, M. Anodically-grown TiO2 nanotubes: Effect of the crystallization on the catalytic activity toward the oxygen reduction reaction. Appl. Surf. Sci. 2017, 412, 447-454. [CrossRef]

36. Wang, L.; Sofer, Z.; Zboril, R.; Cepe, K.; Pumera, M. Phosphorus and Halogen Co-Doped Graphene Materials and their Electrochemistry. Chem.-Eur. J. 2016, 22, 15444-15450. [CrossRef]

37. Dong, Q.; Zhuang, X.; Li, Z.; Li, B.; Fang, B.; Yang, C.; Xie, H.; Zhang, F.; Feng, X. Efficient approach to iron/nitrogen co-doped graphene materials as efficient electrochemical catalysts for the oxygen reduction reaction. J. Mater. Chem. A 2015, 3, 7767-7772. [CrossRef]

38. Liu, R.; Wu, D.; Feng, X.; Müllen, K. Nitrogen-Doped Ordered Mesoporous Graphitic Arrays with High Electrocatalytic Activity for Oxygen Reduction. Angew. Chem. Int. Ed. 2010, 49, 2565-2569. [CrossRef]

39. Delmondo, L.; Salvador, G.P.; Muñoz-Tabares, J.A.; Sacco, A.; Garino, N.; Castellino, M.; Gerosa, M.; Massaglia, G.; Chiodoni, A.; Quaglio, M. Nanostructured MnxOy for oxygen reduction reaction (ORR) catalysts. Appl. Surf. Sci. 2016, 388, 631-639. [CrossRef]

40. Rivera, L.M.; García, G.; Pastor, E. Novel graphene materials for the oxygen reduction reaction. Curr. Opin. Electrochem. 2018, 9 , 233-239. [CrossRef]

41. Zhou, X.; Qiao, J.; Yang, L.; Zhang, J. A Review of Graphene-Based Nanostructural Materials for Both Catalyst Supports and Metal-Free Catalysts in PEM Fuel Cell Oxygen Reduction Reactions. Adv. Energy Mater. 2014, 4, 1301523. [CrossRef]

42. Camisasca, A.; Sacco, A.; Brescia, R.; Giordani, S. Boron/Nitrogen-Codoped Carbon Nano-Onion Electrocatalysts for the Oxygen Reduction Reaction. ACS Appl. Nano Mater. 2018, 1, 5763-5773. [CrossRef]

43. Massaglia, G.; Margaria, V.; Sacco, A.; Castellino, M.; Chiodoni, A.; Pirri, F.C.; Quaglio, M. N-doped carbon nanofibers as catalyst layer at cathode in single chamber Microbial Fuel Cells. Int. J. Hydrogen Energy 2019, 44, 4442-4449. [CrossRef]

44. Wu, G.; Santandreu, A.; Kellogg, W.; Gupta, S.; Ogoke, O.; Zhang, H.; Wang, H.-L.; Dai, L. Carbon nanocomposite catalysts for oxygen reduction and evolution reactions: From nitrogen doping to transition-metal addition. Nano Energy 2016, $29,83-110$. [CrossRef]

45. Jaouen, F.; Proietti, E.; Lefevre, M.; Chenitz, R.; Dodelet, J.-P.; Wu, G.; Chung, H.T.; Johnston, C.M.; Zelenay, P. Recent advances in non-precious metal catalysis for oxygen-reduction reaction in polymer electrolyte fuel cells. Energy Environ. Sci. 2011, 4, 114-130. [CrossRef] 